\title{
Molecular mechanisms of ginsenoside Rp1-mediated growth arrest and apoptosis
}

\author{
ASHOK KUMAR ${ }^{1}$, MADHU KUMAR ${ }^{1}$, TAE-YOON PARK ${ }^{2}$, MYUNG-HWAN PARK $^{2}$, TADASHI TAKEMOTO $^{3}$, \\ TOKIO TERADO ${ }^{3}$, MASARU KITANO $^{4}$ and HIROSHI KIMURA ${ }^{3}$ \\ ${ }^{1}$ Radiation and Cancer Biology Lab, University of Rajasthan, Jaipur, India; ${ }^{2}$ Ambo Institute, Seoul, Korea; \\ ${ }^{3}$ Department of Molecular Genetics in Medicine, Shiga University of Medical Science, Shiga; \\ ${ }^{4}$ Safety Management of Chemical Substances, Department of Industrial Chemistry, \\ Meiji University, Kanagawa, Japan
}

Received April 1, 2009; Accepted May 26, 2009

DOI: 10.3892/ijmm_00000243

\begin{abstract}
Ginsenoside Rp1, a semi-synthesized ginseng saponin, was shown to have chemopreventive action and antimetastatic potential. However, the molecular mechanisms of Rp1 on cell growth and death are not fully understood. In this study, the antiproliferative effect of Rp1 on HeLa cells in vitro was investigated. Treatment with Rp1 at $40 \mu \mathrm{M}$ inhibited the proliferation and partial accumulation of cells at the G1 phase. Rp1-mediated G1 arrest was accompanied by decreased expression of cyclin D1, E, and A and increased expression of p21 without any significant change in p53 or phospho-p53 (Ser15). On the other hand, prolonged incubation with Rp1 at $40 \mu \mathrm{M}$ caused apoptosis and activation of caspase-3, -8 , and -9 . The participation of these three caspases in apoptosis was more clearly shown in experiments using inhibitors, which markedly prevented Rp1-induced apoptosis in the case of each caspase. Cleavage of the polyADP-ribose polymerase, often used as an apoptotic marker, was also found in Rp1-induced apoptosis. Among Bcl-2 family proteins (Bad, Bax, Bid, Bcl-2), Bax and Bid were activated by Rp1 treatment, which resulted in the release of cytochrome $c$ from mitochondria, following activation of caspase-9. These observations indicate that multiple cell cycle regulatory proteins and apoptosis-inducing proteins are regulated by $\mathrm{Rp} 1$ and contribute to Rp1-induced growth arrest and apoptosis.
\end{abstract}

\section{Introduction}

A number of plant glycosides were reported to have biological activities (1-4). The chronic intake of Panax ginseng C.A.

Correspondence to: Dr Hiroshi Kimura, Department of Molecular Genetics in Medicine, Shiga University of Medical Science, Otsu, Shiga 520-2192, Japan

E-mail: kimurah@belle.shiga-med.ac.jp

Key words: ginsenoside, apoptosis, cell cycle, Bcl-2 family proteins, mitochondria
Meyer has been associated with a decreased incidence of cancers that lack organ specificity, as well as cancers of the lung, stomach, liver, colorectum, and pancreas $(5,6)$. Panax ginseng ingredients with anticarcinogenic and antimutagenic activities were identified as minor components in red ginseng (steamed and air-dried Panax ginseng) including ginsenosides $\operatorname{Rg} 3, \operatorname{Rg} 5$ and $\operatorname{Rh} 2(7,8)$. The molecular mechanisms of active ingredients were also studied (9-13). Among ginsenosides, Rg3 was developed as an anticancer drug for treating lung and liver cancers in China (14). Ginsenoside Rg5 showed more potent chemopreventive and antitumor action than ginsenoside $\operatorname{Rg} 3(7,15)$, but was somewhat unstable in a pure form (16). Therefore, we need to synthesize ginsenosides Rp1 [3-O-ß-D-Glucopyranosyl ( $1 \rightarrow 2)$ - 3 -D-glucopyranosyl dammarane-3ß, 12ß-diol] with chemopreventive activity and stability, to improve the anti-tumor activity of $\operatorname{Rg} 3$ and its congeners by chemical modifications.

Various types of ginsenosides consist of totally different molecules on the basis of their chemical structure, such as the number of sugars attached to the backbone and part of the side chain of the molecules. Furthermore, Rp1 has $\mathrm{C}_{20}$-dehydroxy and saturated side chains whereas $\operatorname{Rg} 3, \operatorname{Rg} 5$ and $\mathrm{Rh} 2$ have unsaturated double bonds (17). Rp1 has been shown to have chemopreventive effects on mouse skin papilloma (18). Rp1 is proved to be 10x more active and is more stable than $\operatorname{Rg} 3$ and Rh2. Ginsenoside Rp1 was prepared on a large scale and high yield as a stable form from ginsenoside $\operatorname{Rg} 5$ by reduction with hydrogenation (17). Molecular mechanisms of Rp1 on cell growth and death are not fully understood. The present investigation is an attempt to evaluate the molecular mechanism of Rp1-mediated growth arrest and apoptosis.

\section{Materials and methods}

Chemicals. General caspase inhibitor [Z-Val-Ala-Asp-fmk (Z-VAD-fmk)], caspase-3 inhibitor [Z-Asp-Glu-Val-Aspfmk (Z-DEVD-fmk)], caspase-8 inhibitor [Z-Ile-Glu-ThrAsp-fmk (Z-IETD-fmk)], and caspase-9 inhibitor [Z-LeuGlu-His-Asp-fmk (Z-LEHD-fmk)] were purchased from Calbiochem (San Diego, CA). Antibodies against human caspase-3, -8, -9, polyADP-ribose polymerase (PARP), Bad, 
Bax, Bid, Bcl-2, cytochrome $c$, cyclin D1 and A, p21, p53, phospho-p53 (Ser15), cytochrome oxidase IV (CoxIV), and tubulin were obtained from Cell Signaling Technology (Beverly, MA), and anti B-actin antibody was purchased from Sigma (St. Louis, MO). Anti-cyclin E antibody was obtained from BD Pharmingen (San Jose, CA). All other chemicals were obtained from Nakalai Tesque (Kyoto, Japan). Rp1 was prepared as reported $(17,18)$. Briefly, ginsenoside Rg5 was prepared in a high yield by citric acid hydrolysis of protopanaxadiol ginsenosides fraction in ethanol, and followed by silica gel column chromatographic purification. Ginsenoside Rg5 was hydrogenated on Palladium/charcoal under hydrogen to give ginsenoside Rp1 in a quantitative yield.

Cell line and cell culture. HeLa cells (a doubling time of 20$24 \mathrm{~h}$ ) were used in the present investigation. The cell line was maintained in Dulbecco's minimum essential medium (DMEM) with $10 \%$ fetal bovine serum in a humidified $\mathrm{CO}_{2}$ incubator in $5 \% \mathrm{CO}_{2}$ in air at $37^{\circ} \mathrm{C}$.

Antiproliferative activity. HeLa cells $\left(10^{5}\right.$ cells $)$ were plated into $10-\mathrm{cm}$ Petri dishes and incubated for $24 \mathrm{~h}$. The cells were then treated with $40 \mu \mathrm{M}$ Rp1 for different times $(7,14,24,38$, and $48 \mathrm{~h}$ ), or treated with different concentrations (10, 20, 30, 35, 40 , and $50 \mu \mathrm{M})$ for $48 \mathrm{~h}$. The cytotoxicity of Rp1 was assessed by counting cells attached to dishes and those detached from dishes.

Apoptosis. HeLa cells were cultured with various concentrations of Rp1 for different times. Cells detached from dishes and those attached to dishes were combined and used for analysis of apoptosis. Prior to 4'-6-diamidine-2-phenyl indole (DAPI) staining, the cells were fixed with $70 \%$ ethanol and then washed twice with phosphate-buffered saline. DAPI $(10 \mu \mathrm{g} / \mathrm{ml})$ was added to the fixed cells. After incubation for $1 \mathrm{~h}$, cells were visualized under a fluorescence microscope. Apoptotic cells were identified by condensation and fragmentation of nuclei.

Cell cycle analysis. Cell cycle distribution was detected using the CycleTest Plus DNA Reagent kit (Becton Dickinson, MA) with a BD LSR flow cytometer system, CellQuest, and ModiFit 3.1 (Becton Dickinson, MA). In brief, HeLa cells were collected after treatment with $40 \mu \mathrm{M} \mathrm{Rp} 1$ for $0,7,14$, 24 , and $48 \mathrm{~h}$ and fixed in $70 \%$ ethanol at $-20^{\circ} \mathrm{C}$ for $18 \mathrm{~h}$. The cells were washed twice with $\mathrm{PBS}$ and then pelleted by centrifugation at $400 \mathrm{x}$ g. The cell pellets were incubated with $250 \mu \mathrm{l}$ of solution A (trypsin in a spermine tetrahydrochloride detergent buffer) at room temperature for $10 \mathrm{~min}, 200 \mu \mathrm{l}$ of solution B (trypsin inhibitor and ribonuclease A in citrate stabilizing buffer with spermine tetrahydrochloride) at room temperature for $10 \mathrm{~min}$, and $200 \mu \mathrm{l}$ of solution $\mathrm{C}$ (propidium iodide and spermine tetrahydrochloride in citrate-stabilizing buffer) in the dark at $4^{\circ} \mathrm{C}$ for $10 \mathrm{~min}$. Cells were then analyzed by BD LSR flow cytometry.

Caspase-inhibitor assay. The effects of a general caspase inhibitor (Z-VAD-fmk) and of an inhibitor of caspase-3 (ZDEVD-fmk), caspase-8 (Z-IETD-fmk) or caspase-9 (ZLEHD-fmk) on Rp1-induced apoptosis were examined. Cells were incubated with Rp1 at $40 \mu \mathrm{M}$ and each inhibitor at $40 \mu \mathrm{M}$ for $48 \mathrm{~h}$. Cells were fixed with $70 \%$ ethanol and used for analysis of apoptosis, as described above.

Western blotting. After incubation with Rp1, cells floating in culture medium and cells attached to dishes were collected by centrifugation and scraping, respectively, and combined. Briefly, cells were lysed in RIPA buffer (1\% Triton X-100, $150 \mathrm{mM} \mathrm{NaCl}, 1 \%$ sodium deoxycholate, $0.1 \%$ SDS, $50 \mathrm{mM}$ Tris, pH 7.5) containing $2 \%$ Nakalai protease inhibitor mixture for $30 \mathrm{~min}$ at $0^{\circ} \mathrm{C}$. The supernatant was separated by centrifugation, and protein concentration was determined by CBB protein assay kit (Nakalai Tesque). Proteins (30 $\mu \mathrm{g} /$ well) denatured with sample buffer were separated by 10 or $12 \%$ SDS-polyacrylamide gel. Proteins were transferred onto PVDF transfer membrane (Millipore). The membranes were blocked with a 5\% nonfat dry milk (Nakalai Tesque) in TBS-T (20 mM

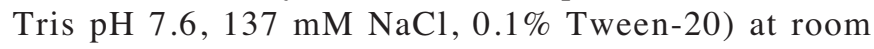
temperature for $1 \mathrm{~h}$ and washed three times with $10 \mathrm{ml}$ of TBS-T for $10 \mathrm{~min}$ and incubated with the primary antibody overnight at $4^{\circ} \mathrm{C}$. The next day, the immunoreaction was continued with the secondary goat anti-rabbit, anti-mouse alkaline phosphatase-conjugated antibody after washing for $1 \mathrm{~h}$ at room temperature. The specific protein bands were detected by CDP-star (Amersham, Piscataway, NJ) .

Cell fractionation. Mitochondrial and cytosol fractions were obtained by an MBI mitochondrial/cytosol fractionation kit (MBI, Watertown, MA) according to the manufacturer's instructions and supplied for Western blot analysis.

\section{Results}

Ginsenoside Rpl suppresses HeLa cell growth. To determine whether or not ginsenoside Rp1 suppresses the HeLa cell growth, we initially assessed the effect of ginsenoside Rp1 on the proliferation of HeLa cells. For cell counting, both cells attached to dishes and those detached from dishes were combined and counted. Ginsenoside Rp1 at $40 \mu \mathrm{M}$ suppressed cell growth at 24, 38 and $48 \mathrm{~h}$ after Rp1 treatment (Fig. 1A). As shown in Fig. 1B, suppression at $48 \mathrm{~h}$ after administration occurred in a dose-dependent manner. Incubation with $30 \mu \mathrm{M}$ for $48 \mathrm{~h}$ had almost no effect, whereas incubation with 35,40 , or $50 \mu \mathrm{M}$ caused not only suppression of cell growth (Fig. 1B) but also detachment of cells from dishes (data not shown).

Induction of apoptosis. For the apoptosis assay, attached and detached cells were combined. Rp1 increased the percentage of apoptosis with increases in time as well as in dose (Fig. 2A and B). Almost all the detached cells had morphological characteristics of apoptosis. On the other hand, no apoptotic cells were found in attached cells.

Cell cycle analysis. HeLa cells were exposed to Rp1 at $40 \mu \mathrm{M}$, and the percentage of cells at each cell cycle stage was analyzed with a flow cytofluorometer. At the start of incubation with Rp1, the percentages of cells at the G1, S, and G2/M phases were $52.5,37.1$, and $10.4 \%$, respectively. During incubation for up to $14 \mathrm{~h}$, the percentage at G1 increased and that at $\mathrm{S}$ decreased, gradually (Fig. 3). At 24 h, the percentage of G2/M decreased, with a concomitant decrease in the percentage of 
A

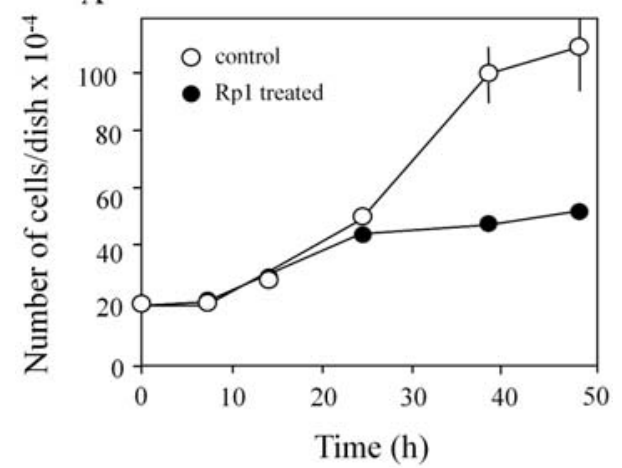

B

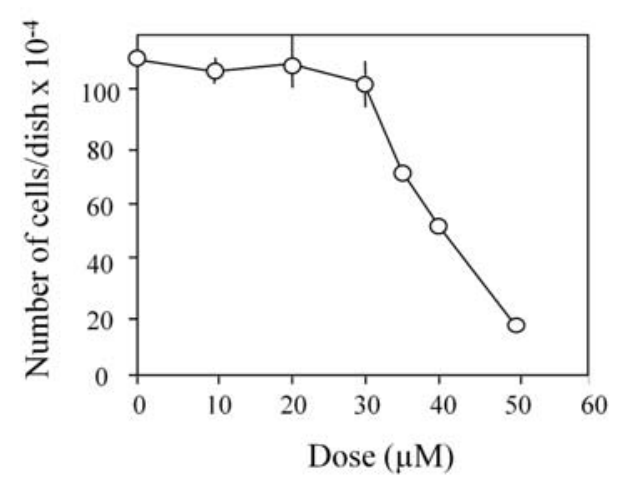

Figure 1. Antiproliferative activity of ginsenoside Rp1 on HeLa cells. Cells were cultured (A) with $40 \mu \mathrm{M}$ of ginsenoside Rp1 for different time intervals (7, 14, 24, 38, and $48 \mathrm{~h})$, or (B) with different concentrations $(10,20,30,35$, 40 , and $50 \mu \mathrm{M}$ ) of ginsenoside Rp1 for $48 \mathrm{~h}$. Rp1 cytotoxicity was assessed by counting cells attached to dishes and those detached from dishes. Vertical bars indicate standard deviations of triplicate samples.

cells, especially in the late $\mathrm{S}$ stage (compare the intensity counts of $>500$ at 14 and $24 \mathrm{~h}$ in Fig. 3). At $48 \mathrm{~h}$, the percentages of $\mathrm{G} 1, \mathrm{~S}$, and $\mathrm{G} 2 / \mathrm{M}$ became close to the respective percentages at the start of incubation. The cells with fluorescent intensity $<290$ (Fig. 3) were thought to be apoptotic and categorized as subG1. The percentage of cells in subG1 is shown in Fig. 3 against the total number of cells. The percentage at subG1 increased gradually with increases in incubation time.

Expression of cyclin D1, E, A, p21, and p53. The expression of cyclin D1, E, and A began to decrease at $7 \mathrm{~h}$ after Rp1 treatment. The expression of each decreased significantly from 14 to $48 \mathrm{~h}$ (Fig. 4). The expression of p21 began to increase at $7 \mathrm{~h}$ and decreased at $48 \mathrm{~h}$. On the other hand, there was no significant change in expression of the p53 gene or in the amount of the phosphorylated form of $\mathrm{p} 53$.

Activation of caspases and cleavage of polyADP-ribose polymerase. It is well documented that members of the caspase family are activated by their own cleavage $(19,20)$. To determine whether or not Rp1 induces caspase activation, the amount of the cleaved form of each caspase was assessed by Western blotting (Fig. 5). In Fig. 5, cleaved forms are shown as $\mathrm{p} 43 / \mathrm{p} 41$ for caspase-8, p37/p35 for caspase-9, and p19/p17 for caspase-3, respectively. Rp1 causes a gradual increase in the cleaved forms of caspase-8, -9 , and -3 at 14 , 24, and $48 \mathrm{~h}$ after Rp1 treatment (Fig. 5). PARP, cleaved in
A
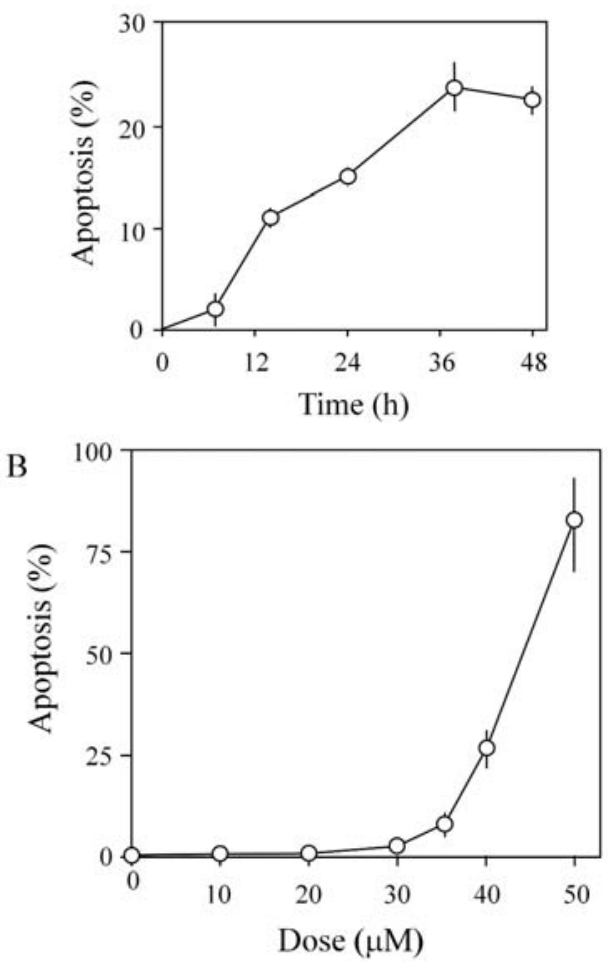

Figure 2. Percentage of apoptotic cells induced by Rp1 in HeLa cells. Cells were cultured (A) with $40 \mu \mathrm{M}$ of ginsenoside Rp1 for different time intervals $(7,14,24,38$ and $48 \mathrm{~h})$, or (B) with different concentrations $(10,20,30,35$, 40 and $50 \mu \mathrm{M}$ ) of ginsenoside Rp1 for $48 \mathrm{~h}$. Apoptotic cells were identified by condensation and fragmentation of nuclei under a fluorescence microscope. Vertical bars indicate standard deviation of triplicate samples.

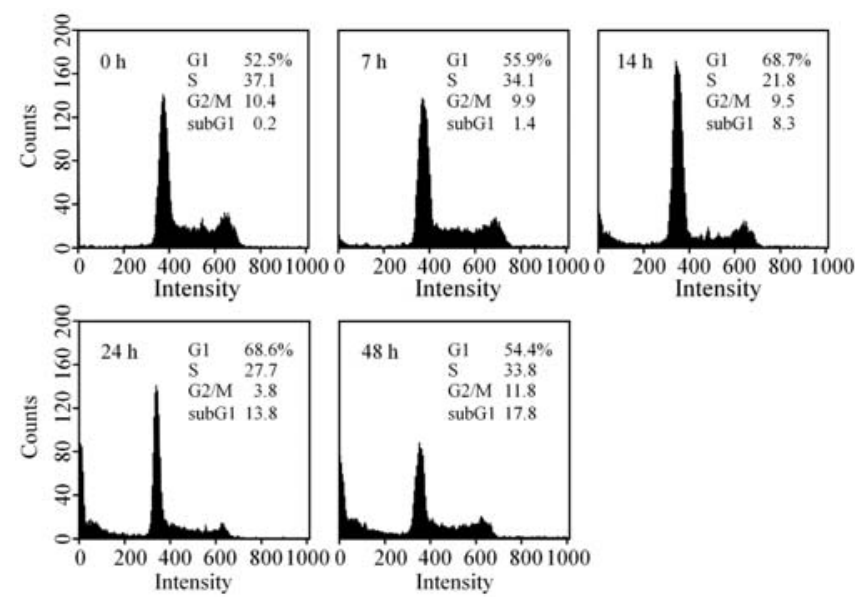

Figure 3. Flow cytometry analysis of HeLa cells. The cells stained with propidium iodide after incubation with Rp1 at $40 \mu \mathrm{M}$ for $0,7,14,24$, and $48 \mathrm{~h}$ were analyzed by flow cytofluorometry. The total number of cells counted in each histogram was 10,000 . The percentage of cells in subG1 was calculated against the total number of cells.

many different systems during apoptosis as a substrate of caspase-3 and -7 (19) was proteolyzed in Rp1-treated cells (p89 in Fig. 5). To clarify whether or not caspase activation was needed for the induction of apoptotic death triggered by Rp1, caspase inhibitors that acted by binding to the active site of each caspase were used. HeLa cells were incubated with Rp1 
$\begin{array}{lllll}0 & 7 & 14 & 24 & 48(\mathrm{~h})\end{array}$

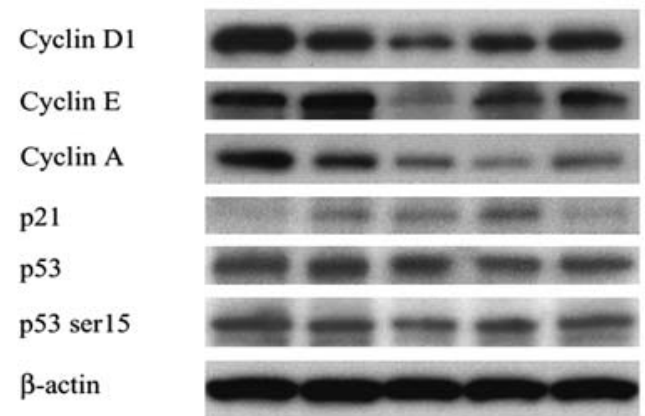

Figure 4. Western blot analysis of the expression of cell cycle-related proteins in HeLa cells. The cells were treated with ginsenoside Rp1 at $40 \mu \mathrm{M}$ for 0,7 , 14,24 , and $48 \mathrm{~h}$.

$\begin{array}{llllll}0 & 7 & 14 & 24 & 48 & (\mathrm{~h})\end{array}$

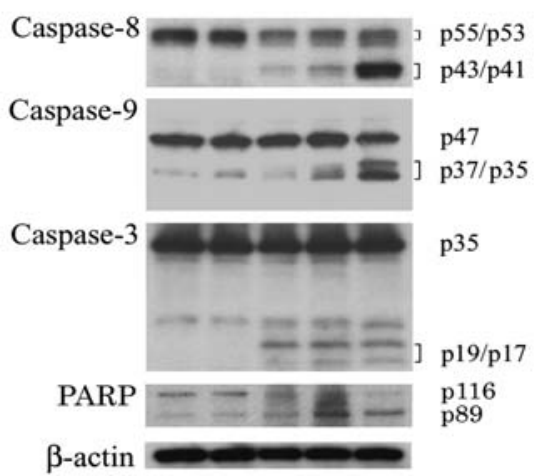

Figure 5. Activation of caspases and cleavage of polyADP-ribose polymerase (PARP) in HeLa cells by Rp1. The cells were treated with ginsenoside Rp1 at $40 \mu \mathrm{M}$ for $0,7,14,24$, and $48 \mathrm{~h}$ and applied to Western blot analysis. The activated (cleaved) forms of caspase- $8,-9$, and -3 are shown as bands at p43/p41, p37/p35, and p19/p17, respectively.

at $40 \mu \mathrm{M}$ and with each caspase inhibitor at $40 \mu \mathrm{M}$ for $48 \mathrm{~h}$ (Fig. 6). Caspase- 3 and -9 inhibitors and the general inhibitor at $40 \mu \mathrm{M}$ inhibited apoptosis to almost the same extent, whereas caspase-8 inhibitor had a slightly smaller effect (Fig. 6).

Activation of Bcl-2 family proteins. A whole cell fraction was used for Western blot analysis (Fig. 7A). There were decreases in the amount of Bid after Rp1 treatment. As the antibody against Bid reacts only with Bid and not with the activated form (truncated) of Bid, the decreases mean that Rp1 truncates Bid. On the other hand, there were no changes in the expression of Bcl-2 or Bax. It is well known that Bax activation is initiated by translocation from cytosol into mitochondria to form dimers $(21,22)$. Then we tested to see whether or not translocation occurs. As shown in Fig. 7B, cytosolic and mitochondrial fractions were used for Western blot analysis. Cytochrome oxidase subunit IV (CoxIV) and tubulin were used as mitochondrial and cytosolic loading controls, respectively. Rp1 decreased the amount of Bax in the cytosolic fraction and increased it in the mitochondrial fraction. On the other hand, the amount of Bad in the cytosolic fraction was almost equivalent to that in the mitochondrial fraction, irrespective of

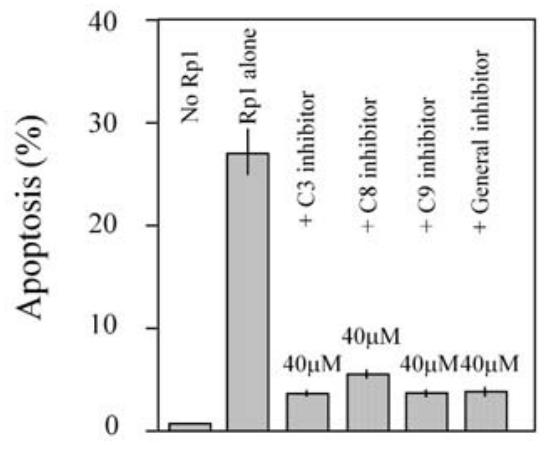

Figure 6. Effects of a general caspase inhibitor (Z-VAD-fmk) and an inhibitor of caspase-3 (Z-DEVD-fmk), caspase-8 (Z-IETD-fmk), or caspase-9 (Z-LEHDfmk) on Rp1-induced apoptosis. The cells were incubated with Rp1 at $40 \mu \mathrm{M}$ and each inhibitor at $40 \mu \mathrm{M}$ for $48 \mathrm{~h}$. Apoptotic cells were identified by condensation and fragmentation of nuclei. Vertical bars indicate means \pm standard deviation of triplicate samples.

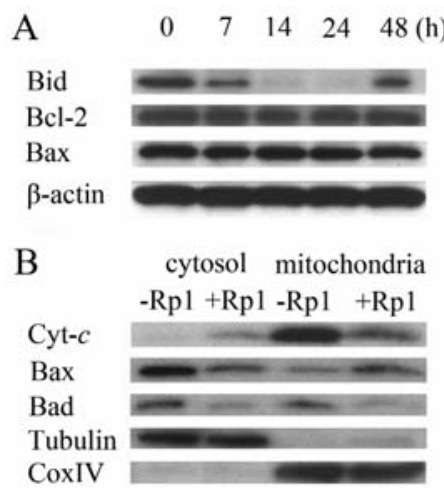

Figure 7. Cleavage of Bid (A), mitochondrial translocation of Bax, and release of cytochrome $c$ from mitochondria (B) in Rp1-treated HeLa cells. The cells were incubated with Rp1 at $40 \mu \mathrm{M}$ for $48 \mathrm{~h}$. Whole cell fractions (A) or cytosol and mitochondrial fractions (B) were applied to Western blot analysis. Cytochrome oxidase subunit IV (CoxIV) and tubulin were used as cytosolic and mitochondrial loading controls.

Rp1 treatment, although Rp1 decreased the amounts in both fractions. It was reported that the translocation of Bad in mitochondria is important for Bad activation (23). We then examined the release of cytochrome $c$ from mitochondria, which is known to cause the activation of caspase-9 (22). Rp1 decreased the amount of cytochrome $c$ in the mitochondrial fraction, concomitant with an increase in the cytosolic fraction.

\section{Discussion}

In the present study we demonstrated that Rp1 inhibited the proliferation of HeLa cells in vitro in a dose-dependent manner. Rp1 significantly inhibited growth at the dose range of 30-40 $\mu \mathrm{M}$ (Fig. 1) with increases in the percentage of apoptosis (Fig. 2). As growth inhibition may involve changes in the progression of cells through the cell cycle, we investigated the profile of the percentage of cells at each stage in the cycle (Fig. 3). There was a partial accumulation of cells in G1 during incubation for 7 and 14 h. Progression through G1 slowed during this incubation, and progression through $\mathrm{S}$ and $\mathrm{G} 2 / \mathrm{M}$ was affected to a lesser extent. At $24 \mathrm{~h}$ there was a slight increase in the percentage of cells at $\mathrm{S}$ and a slight decrease in cells at G2/M. 
At $48 \mathrm{~h}$, the distribution of cells at each stage was almost the same as that at $0 \mathrm{~h}$ (Fig. 3). As shown in Fig. 1A, there was almost no cell proliferation between 24 and $48 \mathrm{~h}$; all stages of the cell cycle slowed up to this incubation time. Rp1 gradually increased the percentage of apoptosis for 7-48 h, whereas there was only slight cell proliferation during that time (Figs. 1A, 2A, and 3). It is then suggested that some fraction of the cells that accumulated in G1 moved into the apoptotic subG1 fraction.

Cell cycle control is a highly regulated process that involves a complex cascade of events. Modulation of the expression and function of cell cycle regulatory proteins provides an important growth mechanism (24). In mammalian cells, distinct cyclins are associated with different cdks, and the expression of cyclins fluctuates throughout the cell cycle. Cyclin D1 is induced by signals for growth, and the expression is a relatively early event during progression through $\mathrm{G} 1$ before the expression of cyclin E (25). As shown in Fig. 4, the amounts of cyclin D1 and $\mathrm{E}$ started to decrease at $7 \mathrm{~h}$, and the rate of reduction peaked at $14 \mathrm{~h}$. There are two possibilities to explain these reductions. Rp1 down-regulated the expression of cyclin D1 and E and/or caused the arrest of cells at an early point in G1 where there is no expression of D1 or E. Expression of p21 is regulated by differentiation signals p53-dependently and -independently (26). p21 inhibits the activity of the G1 cyclin-cdk complex to arrest the cells at G1 (25). As the expression of p21 was enhanced by the incubation of cells with Rp1 for 7, 14, and $24 \mathrm{~h}$ (Fig. 4), p21 may have contributed to the partial accumulation of cells at G1. Expression of cyclin A, which is concerned with DNA replication, was predominant at late $S$ and G2/M. The maximum reduction of cyclin A was found at $24 \mathrm{~h}$ (Fig. 4), which is consistent with decreases in the percentages of cells at late $\mathrm{S}$ and G2/M at $24 \mathrm{~h}$ (Fig. 3). We have no data indicating whether or not $\mathrm{Rp} 1$ down-regulated cyclin A expression. As p53 is known to cause G1 arrest (27) we expected an increase in p53 or in the phosphorylated form of p53 but there was no such change (Fig. 4). It was reported that an increase in the amount of p21 in HeLa cells, with no increase in the amount of p53, caused the arrest of cells at the G1/S boundary (28). Further evidence was attained that p21 mediates apoptosis in a p53-independent manner $(26,28)$.

In spite of the modulation of cell cycle regulatory molecules, apoptosis-mediating molecules are also important in the determination of the Rp1-mediated antitumor effect (Figs. 5-7). Apoptosis is a fundamental form of programmed cell death characterized by a series of morphological features, such as cell shrinkage, chromatin condensation, nuclear fragmentation, and the formation of apoptotic bodies. It is changed by biochemical features, such as the activation of caspase cascades, the expression of Bcl-2 family proteins, and ligand-inducing activation of death receptors (29). Previous reports demonstrated that caspase family proteases play essential roles in apoptosis (30). Caspases are present as inactive proenzymes, most of which are activated by proteolytic cleavage at specific aspartic amino acid sites $(19,20)$. Activation of caspase-3, -8, and -9 during Rp1-induced apoptosis was observed in the present study (Fig. 5). The amount of cleaved forms increased with incubation time (Fig. 5), which may correspond to the increase in the percentage of apoptotic cells (Fig. 2A). Involvement of these caspases in Rp1-induced apoptosis is more clearly shown in the experiment using specific inhibitors (Fig. 6). Each inhibitor, except that for caspase-8, inhibited Rp1induced apoptosis to almost the same extent, whereas the inhibitor for caspase- 8 had a slightly lower effect. There are several pathways to activate caspase-3 (29). In one pathway, procaspase- 3 is cleaved by the activated form of caspase- 9 in response to agents or insults. The activation of caspase-9 is initiated by the release of cytochrome $c$ from mitochondria (mitochondrial pathway) under the control of Bcl-2 family proteins (positively Bax, Bak, Bad and negatively Bcl-2, Bcl-XL, etc.) (22). In another pathway, caspase- 8 is activated in response to extracellular apoptosis-inducing ligands such as tumor necrosis factor $\alpha$ or Fas ligand in a complex of receptors and cytoplasmic death domains (31). Then, activated caspase-8 promotes the mitochondrial pathway via the activation of Bid to cause the activation of caspase- 9 and the subsequent cleavage of procaspase-3. In some cases, caspase- 8 directly attacks procaspase- 3 to cleave it for activation (29). The activation of caspase- 3 then causes proteolysis including that of PARP (Fig. 5) and the fragmentation of DNA molecules to promote apoptosis. In the present study, we investigated the participation of four members of the Bcl-2 family (Bcl-2, Bax, Bid, and $\mathrm{Bad}$ ) in Rp1-induced apoptosis (Fig. 7). These members are modified differently in response to the formation of death ligand-receptor complexes, the depletion of cytokines, or stress by chemical or physical agents (32). Among these four members, the activation of Bid (truncation) and that of Bax (dimerization in mitochondria) were found in Rp1-induced apoptosis, as shown in Fig. 7. The release of cytochrome $c$ from mitochondria was also found in the present study (Fig. 7B). As Bax was activated (Fig. 7B), the mitochondrial pathway may be activated via Bax in response to $\mathrm{Rp} 1$ as a chemical agent. On the other hand, the activation of Bid suggests participation of caspase- 8 in Rp1-induced apoptosis, which is also shown in the experiment using the inhibitor specific for caspase-8 (Fig. 6). Administration of Rh2, did not alter the level of Bcl-2 family proteins (10). This may be one reason for the more potent activity of the ginsenoside Rp1. However, direct cleavage of procaspase- 3 by caspase- 8 may not have occurred in Rp1-induced apoptosis, as the specific inhibitors for caspase-3 and -9 had almost the same effects (Fig. 6). It should be noted that the inhibitor specific for caspase- 8 had lesser effects than those for caspase- 9 and -3 in the repeated experiments (Fig. 6). At least two different pathways may be activated by Rp1 treatment, as mentioned above. In an earlier report (10), it was shown that activation of death receptor DR4 signalling is required for Rh-2 mediated apoptosis. As no activation of caspase- 9 was involved in Rh-2 mediated apoptosis, we did not establish if there was activation of DR4 in Rp1-induced apoptosis. However, investigation on death receptor pathways will be of use to clarify mechanisms in Rp1induced apoptosis.

In conclusion, the present study revealed that $\mathrm{Rp} 1$, a stable form of a potent chemopreventive and antitumor-active ginsenoside $\mathrm{Rg} 5$, has a strong antiproliferative and apoptosisinducing activity in HeLa cells. In a preliminary experiment using HeLa cells, there were cell-killing effects of Rp1 four times more than those of $\operatorname{Rg} 3$ (data not shown). An earlier report showed that Rp1 orally administered to mice to prevent dimethylbenz(a)anthracene-induced papillomagenesis (18). 
The level of some of the carcinogen-metabolizing and antioxidant enzymes is influenced by Rp1 administration, and these changes in levels may contribute to the detoxification of the carcinogen. Here, we showed that Rp1 directly affects cellular proliferation and death by changing the expression and activities of cell cycle- and apoptosis-regulating proteins. It is still unknown to what extent these direct effects on cells contribute to the prevention of chemopapillomagenesis. However, a combination study of in vitro and in vivo would be useful in order to elucidate the anti-calcinogenic activities of the chronic administration of ginseng and of each component.

\section{Acknowledgements}

We are thankful to Shiga University of Medical Science, Shiga, Japan, for providing Ashok Kumar with a Visiting Fellowship.

\section{References}

1. Mann J: Natural products in cancer chemotherapy: past, present and future. Nat Rev Cancer 2: 143-148, 2002.

2. Surh YJ: Cancer chemoprevention with dietary phytochemicals. Nat Rev Cancer 3: 768-780, 2003.

3. Surh YJ, Na HK and Lee SS: Transcription factors and mitogenactivated protein kinases as molecular targets for chemoprevention with anti-inflammatory phytochemicals. Biofactors 21: 103-108, 2004.

4. Wargovich MJ, Woods C, Hollis DM and Zander MF: Herbals, cancer prevention and health. J Nutr 131: 3034-3036, 2001.

5. Yun TK: Panax ginseng-non-organ-specific cancer preventive? Lancent Oncol 2: 49-55, 2001.

6. Yun TK, Choi SY and Yun HY: Epidemiological study on cancer prevention by ginseng: are all kinds of cancers preventable by ginseng? J Kor Med Sci 16: 19-27, 2001.

7. Yun TK, Lee YS, Lee YH, Kim SI and Yun HY: Anticarcinogenic effect of Panax ginseng C.A. Meyer and identification of active compounds. J Kor Med Sci 16: S6-S18, 2001.

8. Yun TK: Experimental and epidemiological evidence on nonorgan specific cancer preventive effect of Korean ginseng and identification of active compounds. Mutat Res 523-524: 63-74, 2003.

9. Wang CZ, Xie JT, Zhang B, Ni M, Fishbein A, Aung HH, Mehendale SA, Du W, He TC and Yuan CS: Chemopreventive effects of Panax notoginseng and its major constituents on SW480 human colorectal cancer cells. Int J Oncol 31: 1149-1156, 2007.

10. Cheng CC, Yang SM, Huang CY, Chen JC, Chang WM and Hsu SL: Molecular mechanisms of ginsenoside Rh2-mediated G1 growth arrest and apoptosis in human lung adenocarinoma A549 cells. Cancer Chemother Pharmacol 55: 531-540, 2005.

11. Lee KY, Lee YH, Kim SI, Park JH and Lee SK: GinsenosideRg5 suppresses cyclin E-dependent protein kinase activity via up-regulating p21 Cip/WAF1 and down-regulating cyclin E in SK-HEP-1 cells. Anticancer Res 17: 1067-1072, 1997.

12. Surh YJ, Na HK, Lee JY and Keum YS: Molecular mechanisms underlying anti-tumor promoting activities of heat-processed Panax ginseng C.A. Meyer. J Kor Med Sci 16 : 38-41, 2001.
13. Surh YJ, Lee JY, Choi KJ and Ko SR: Effects of selected ginsenosides on phorbol ester-induced expression of cyclooxygenase- 2 and activation of NF- $\mathrm{KB}$ and ERK1/2 in mouse skin. Ann NY Acad Sci 973: 396-401, 2002.

14. Ministry of Health: Rg-3 shenyi Jiaonang. In: Health News. Chinese Ministry of Health, Beijing, May, 2000.

15. Park IH, Piao LZ, Kwon SW, Lee YJ, Cho SY, Park MK and Park JH: Cytotoxic dammarane glycosides from processed ginseng. Chem Pharm Bull 50: 538-540, 2002.

16. Han BH, Park MH, Han YN, Woo LK, Sankawa U, Yahara S and Tanaka O: Degradation of ginseng saponins under mild acidic conditions. Planta Med 44: 146-149, 1982.

17. Park TY, Park MH, Shin WC, Rhee MH, Seo DW, Cho JY and Kim HN: Anti-metastatic potential of ginsenoside Rp1, a novel ginsenoside derivative. Biol Pharm Bull 31: 1802-1805, 2008

18. Kumar A, Kumar M, Panwar M, Samarth RM, Park TY, Park MH and Kimura H: Evaluation of chemopreventive action of ginsenoside Rp1. Biofactors 26: 29-43, 2006.

19. Cohen GM: Caspases: the executioners of apoptosis. Biochem J 326: 1-16, 1997.

20. Creagh EM, Conroy $\mathrm{H}$ and Martin SJ: Caspase-activation pathways in apoptosis and immunity. Immunol Rev 193: 10-21, 2003 .

21. Er E, Oliver L, Cartron PE, Juin P, Manon S and Vallette FM: Mitochondria as the target of the pro-apoptotic protein Bax. Biochim Biophys Acta 1757: 1301-1311, 2006.

22. Kroemer G, Galluzzi L and Brenner C: Mitochondrial membrane permeabilization in cell death. Physiol Rev 87: 99$163,2007$.

23. Chen C, Yan C, Sun Q, Yao L, Jian Y, Lu J and Gu J: Induction of apoptosis by $\mathrm{p} 110 \mathrm{C}$ requires mitochondrial translocation of the proapoptotic BCL-2 family member BAD. FEBS Lett 580: 813-821, 2006.

24. Nigg EA: Cyclin-dependent protein kinases: key regulators of the eukaryotic cell cycle. Bioessays 17: 471-480, 1995.

25. Sherr CJ and Roberts JM: Inhibitors of mammalian G1 cyclindependent kinases. Genes Dev 9: 1149-1163, 1995.

26. Wu Q, Kirschmeier P, Hockenberry T, Yang TY, Brassard DL, Wang L, McClanahan T, Black S, Rizzi G, Musco ML, Mirza A and Liu S: Transcriptional regulation during p21 $1^{\mathrm{WAF} 1 / \mathrm{CIP1}}$-induced apoptosis in human ovarian cancer cells. J Biol Chem 277: 36329-36337, 2002.

27. Levine AJ, Hu W and Feng Z: The P53 pathway: what questions remain to be explored? Cell Death Differ 13: 10271036, 2006.

28. Li $\mathrm{H}$ and $\mathrm{Wu} \mathrm{X}$ : Histone deacetylase inhibitor, Trichostatin A, activates $\mathrm{p} 21^{\mathrm{WAF} / \mathrm{CIP} 1}$ expression through downregulation of c-myc and release of the repression of $\mathrm{c}-\mathrm{myc}$ from the promoter in human cervical cancer cells. Biochim Biophys Res Commun 324: 860-867, 2004.

29. Chowdhury I, Tharakan B and Bhat GK: Current concepts in apoptosis: the physiological suicide program revisited. Cell Mol Biol Lett 11: 506-525, 2006.

30. Kumar S: Caspase function in programmed cell death. Cell Death Differ 14: 32-43, 2007.

31. Ashkenazi A and Dixit VM: Death receptors: signaling and modulation. Science 281: 1305-1308, 1998.

32. Thomadaki $\mathrm{H}$ and Scorilas $\mathrm{A}$ : $\mathrm{Bcl} 2$ family of apoptosis-related genes: functions and clinical implications in cancer. Crit Rev Clin Lab Sci 43: 1-67, 2006. 